\title{
The effect of blue dishware versus white dishware on food intake and eating challenges among residents living with dementia: a crossover trial
}

\author{
Rachael Donnelly ${ }^{10}$, Cindy Wei ${ }^{1}$, Jill Morrison-Koechl ${ }^{1}$ and Heather Keller ${ }^{1,2^{*}}$
}

\begin{abstract}
Objective: Residents living with dementia (RLWD) often experience changes in their visual perception, which could reduce food intake. Inadequate food intake is known to cause malnutrition, which increases the risk of hospitalization, morbidity, and mortality. This study evaluated the effectiveness of using blue dishware compared to white dishware to improve food intake and mitigate eating challenges among 18 RLWD (mean age $84.6 \pm 7.9$ years, $72.2 \%$ female).

Results: A within-within person crossover design determined differences in food intake and eating challenges between blue and white dishware conditions. Five participants responded to the blue dishware and increased their average food intake by $\geq 10 \%$. Responders were not different from non-responders in terms of demographic or health characteristics. The proportion of eating challenges experienced was not significantly different between the blue and white dishware conditions. Percent food intake was significantly greater at lunch ( $83.5 \pm 19.0 \%)$ compared to dinner $(75.8 \pm 22.1 \% ; p<0.0001)$, regardless of dishware condition. However, there were no significant differences for food intake between the dishware conditions, even after matching food choices. Promoting food intake and reducing eating challenges in RLWD likely needs multi-component interventions targeting meal quality, meal access, and mealtime experience.

Trial registration ClincialTrials.gov Identifier: NCT04298788. Retrospectively registered: 6 March 2020, https://clinicaltr ials.gov/ct2/show/NCT04298788?term $=$ NCT04298788\&draw=2\&rank=1.
\end{abstract}

Keywords: Food intake, Eating challenges, Dementia, Dining, Blue, Dishware, Physical environment

\section{Introduction}

Approximately 50 million people live with dementia worldwide, with 10 million new diagnoses annually [1]. Dementia is characterized by cognitive impairments [1], including declines in memory, executive function, and communication [2]. Eventually, it becomes difficult for persons with dementia to perform activities of daily

*Correspondence: hkeller@uwaterloo.ca

${ }^{2}$ Schlegel-University of Waterloo Research Institute for Aging, 250

Laurelwood Drive, Waterloo, ON N2J OE2, Canada

Full list of author information is available at the end of the article living [1-4], and many enter residential care to receive support $[3,5,6]$.

Inadequate intake of energy, protein, and micronutrients is common in residential care [7-13], and poor food intake and malnutrition are prevalent among residents living with dementia (RLWD) [7]. An estimated 52\% of RLWD are malnourished [7], compared to $19-44 \%$ of residents without dementia [7-10]. Malnutrition is associated with hospitalization, impaired quality of life, and increased risk of falls, morbidity, and mortality [3, 12 , 14-17].

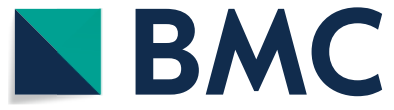

(c) The Author(s) 2020. This article is licensed under a Creative Commons Attribution 4.0 International License, which permits use, sharing, adaptation, distribution and reproduction in any medium or format, as long as you give appropriate credit to the original author(s) and the source, provide a link to the Creative Commons licence, and indicate if changes were made. The images or other third party material in this article are included in the article's Creative Commons licence, unless indicated otherwise in a credit line to the material. If material is not included in the article's Creative Commons licence and your intended use is not permitted by statutory regulation or exceeds the permitted use, you will need to obtain permission directly from the copyright holder. To view a copy of this licence, visit http://creativeco mmons.org/licenses/by/4.0/. The Creative Commons Public Domain Dedication waiver (http://creativecommons.org/publicdomain/ zero/1.0/) applies to the data made available in this article, unless otherwise stated in a credit line to the data. 
Disease- and age-related declines in vision can contribute to decreased food intake among RLWD [3, 6, 9, 18-24]. Persons with dementia experience deficits in contrast sensitivity and colour discrimination [19-23]. Thus, insufficient contrast between food items and dishware (e.g., bowls, plates) may reduce food intake [19, 21, $24,25]$ and increase eating challenges $[9,17,18,21,24$, 25].

Simple, effective interventions that improve food intake among RLWD are desirable. Yet, few studies have investigated how contrast manipulations within the dining room affect resident food intake and eating challenges $[19,25]$. Dunne et al. [19] used high-contrast dishware among 9 male residents with Alzheimer's disease, and found that the enhanced contrast significantly increased food and fluid intake.

Further investigation is needed to corroborate this study, using a larger sample that includes women and attempts to match food choices. The objective of the present study was to determine if blue dishware increases food intake and reduces eating challenges among RLWD in a typical residential care dining room, using a crossover design with matched meals.

\section{Main text}

\section{Setting and participants}

Participants were recruited from a memory care unit within a single retirement home in Southern Ontario, Canada. All unit residents had dementia. Residents were eligible if they could eat independently, and if they typically ate in the dining room or adjoining lounge. The unit coordinator posted study flyers and emailed substitute decision-makers (i.e., family and friends), who were connected with researchers for informed consent. In accordance with the Declaration of Helsinki and the TriCouncil Policy Statement, participants were asked before each meal whether they assented to have their food and dishware weighed [26]. Ethics clearance was provided by the University of Waterloo Office of Research Ethics (ORE\#40986).

The unit coordinator collected information from participants' health records, including age, sex, length of admission on the memory unit (admission to study end date), and current medications. The unit coordinator assessed cognitive status using the Montreal Cognitive Assessment (MoCA; maximum score $=30$ ) [27]; lower scores represent higher cognitive impairment [27].

\section{Dishware}

Blue dishware was ordered from Steelite International $\odot$ in the shade Blue Lagoon (Fig. 1a), which was the only non-patterned blue dishware commercially available for residential care. White dishware (Manaco White;

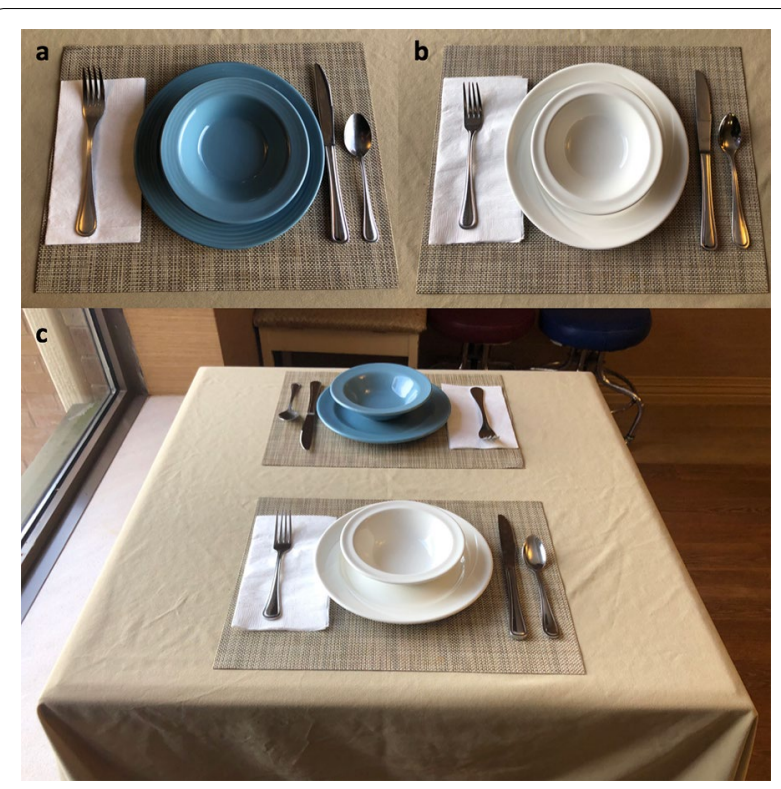

Fig. 1 Blue and white dishware on a set table. a Blue Lagoon bowl (weight: $411.4 \mathrm{~g}$ and inside diameter: $13.6 \mathrm{~cm}$ ) and plate (weight: $598.3 \mathrm{~g}$ and diameter: $23.8 \mathrm{~cm}$ ) on a beige placemat and tablecloth. b Monaco White bowl (weight: $298.9 \mathrm{~g}$ and inside diameter: $13.4 \mathrm{~cm}$ ) and plate (weight: $539.6 \mathrm{~g}$ and diameter: $23.8 \mathrm{~cm}$ ) on a beige placemat and tablecloth. c Blue and white dishware set together on a table with a beige placemat and tablecloth.

Fig. 1b) from the same supplier was already present on the unit. Researchers weighed and measured blue and white dishware to calculate average weight. The blue and white dishware were similar in size (blue bowls: $13.6 \mathrm{~cm}$; white bowls: $13.4 \mathrm{~cm}$; blue plates: $23.8 \mathrm{~cm}$; white plates: $23.8 \mathrm{~cm}$; Fig. 1).

\section{Design}

The unit used a 4-week menu cycle. Lunches and dinners were observed for 4 days per week of menu cycle weeks 3 and 4 . These weeks had an increased frequency of low-contrast food offerings (e.g., mashed potatoes, white rice). Data collection was completed in 2 rounds. Meals (day of week and menu) were matched to compare blue and white dishware. Dishware conditions were alternated at each meal to reduce the impact of acute illness, dementia progression, or health deterioration on food intake. Data were collected at 32 meals (16 blue, 16 white). The mean number of participant observations was $19 \pm 2$ meals, with 359 observations in total (178 blue condition, 181 white condition; 176 lunches, and 183 dinners). Participants missed observations due to illness, eating in their room, eating with a loved one, or dissent for observation at a meal. Lunches included soup and a main course, while dinners included only a main course. 
Meal timing and the number of staff, family, and volunteers present were recorded.

\section{Food intake}

Dishes were labelled with participant numbers, and food and dishware were weighed pre- and post-meal using a ULINE $^{\mathrm{TM}}$ Easy-Count food scale accurate to 0.1 grams. After subtracting the average weight of the dishware, the weight of the food consumed was determined by subtracting the leftovers from the food provided. The weight of the food consumed was divided by the weight of the food offered and multiplied by 100 to generate percent food intake.

It was hypothesized that some RLWD may be more likely than others to increase their food intake with blue dishware (i.e., responders). The mean difference in average percent food intake for the dishware conditions was doubled to calculate the threshold value for responders. The threshold value was calculated to be $\mathrm{a} \geq 10 \%$ increase in food intake with the blue dishware.

\section{Eating challenges}

Participants were observed to determine if eating challenges were present using a standardized checklist [12]: using tableware improperly (e.g., utensils, napkins); spilling food; spitting out food; chewing or swallowing difficulties; falling asleep; or wandering. Eating challenges were recorded as dichotomous variables, and the number of eating challenges observed per participant was totaled for each meal. The total number of eating challenges observed during the study was low. Therefore, the proportion of meals where any eating challenges were observed was compared between the dishware conditions.

\section{Sample size calculation}

A one-way repeated measures within-person analysis of variance (ANOVA) was used to compute required sample size, as there is no current estimation guideline for a two-factor repeated measures within-within design. Based on Dunne et al., the expected effect size was a $25 \%$ increase in food intake with the blue dishware. The power and alpha level were set at $80 \%$ and 0.05 , respectively. At least 16 observations were expected per participant, with a correlation of 0.5 for repeated measurements. The estimated sample size for this study was 11 .

\section{Data analysis}

SAS Studio 3.8 (SAS Institute Inc., Cary, North Carolina, United States) was used. Descriptive and bivariate (i.e., Chi square, $t$ test) statistics characterized the sample and compared responders to non-responders. A Chi square test compared the proportion of eating challenges experienced during the dishware conditions. A two-factor repeated measures within-within ANOVA compared percent food intake between the dishware conditions and meals. Covariates were: age; sex; MoCA score; length of admission; number of medications; and the number of staff, volunteers, and family present at the meal. A paired t-test compared percent food intake at meals where participants selected the same food choices during matched data collection days. An alpha level of 0.05 was used for all tests.

\section{Results}

Table 1 summarizes the demographic and health characteristics of the sample. Mean MoCA score was consistent with moderate-to-severe dementia [27]. The mean difference in average percent food intake for the entire sample was $4.8 \pm 7.0 \%$ with the blue dishware. Five participants were classified as responders, but there were no differences between responders and non-responders for demographic or health characteristics. Responders had a significantly greater mean difference in average percent food intake compared to non-responders $(p=0.0002$; Table 1$)$ for the blue and white conditions. Eating challenges occurred during 48 of the 359 observed meals. Wandering, using tableware improperly, and falling asleep were the most common eating challenges observed. Yet, the number of eating challenges observed was not significantly different between the blue (14.0\%) and white $(9.4 \%)$ dishware conditions $(p=0.17)$.

Table 2 displays mean percent food intake for all meals (unmatched and matched). Percent food intake was significantly greater at lunch compared to dinner $(p<0.0001)$, regardless of dishware condition. When comparing all meals, no significant differences in percent

\section{Table 1 Demographic and health characteristics}

\begin{tabular}{|c|c|c|c|}
\hline & All & Responders & Non-responders \\
\hline Number of residents, $n$ & 18 & 5 & 13 \\
\hline Age, years ${ }^{a}$ & $84.6 \pm 7.9$ & $85.0 \pm 8.3$ & $84.6 \pm 8.5$ \\
\hline \multicolumn{4}{|l|}{ Sex } \\
\hline Male, \% ${ }^{b}$ & $27.8(5)$ & $20.0(1)$ & $30.8(4)$ \\
\hline Female, $\%^{b}$ & $72.2(13)$ & $80.0(4)$ & $69.2(9)$ \\
\hline MoCA score, points ${ }^{\mathrm{a}}$ & $12.5 \pm 5.0$ & $13.4 \pm 3.9$ & $12.3 \pm 5.9$ \\
\hline Length of admission, years ${ }^{a}$ & $2.3 \pm 2.4$ & $1.8 \pm 1.2$ & $2.6 \pm 2.8$ \\
\hline Medications, $\#^{a}$ & $9.5 \pm 2.5$ & $10.0 \pm 1.2$ & $9.2 \pm 2.9$ \\
\hline $\begin{array}{c}\text { Mean difference in average } \\
\text { percent food intake, \%a }\end{array}$ & $4.8 \pm 7.0$ & $13.2 \pm 2.2^{*}$ & $1.6 \pm 5.2$ \\
\hline
\end{tabular}

a Continuous variables are expressed using their mean and standard deviation

b Categorical variables are expressed using percentages

* Responders had a significantly higher mean difference in average percent food intake compared to non-responders, $p<0.05$ 
Table 2 Mean percent food intake for all meals and matched meals

\begin{tabular}{|c|c|c|}
\hline & $\begin{array}{l}\text { All meals }{ }^{a} \\
\text { Mean } \pm \text { SD }\end{array}$ & $\begin{array}{l}\text { Matched meals } \\
\text { Mean } \pm \text { SD }\end{array}$ \\
\hline Number of residents, $n$ & 17 & 15 \\
\hline Number of observations, $n$ & 332 & 53 \\
\hline $\begin{array}{l}\text { Mean percent food intake at blue } \\
\text { meals, } \%\end{array}$ & $82.1 \pm 19.7$ & $87.5 \pm 14.8$ \\
\hline $\begin{array}{l}\text { Mean percent food intake at white } \\
\text { meals, } \%\end{array}$ & $77.1 \pm 21.9$ & $83.8 \pm 18.4$ \\
\hline $\begin{array}{l}\text { Mean percent food intake at } \\
\text { lunches, } \%\end{array}$ & $83.5 \pm 19.0^{*}$ & - \\
\hline $\begin{array}{l}\text { Mean percent food intake at din- } \\
\text { ners, \% }\end{array}$ & $75.8 \pm 22.1$ & - \\
\hline
\end{tabular}

${ }^{a}$ The two-way repeated measures ANOVA compared percent food intake between all meals (unmatched and matched). One participant was excluded from this analysis since they were only available for observation during dinners. Other meal observations were excluded from this analysis if covariate data was missing

b The paired t-test compared percent food intake between matched blue and white meals for 15 participants

*Percent food intake was significantly higher at lunch compared to dinner, $p<0.05$

food intake were found for blue or white dishware conditions $(p=0.06)$. Fifteen participants selected the same food choices during 53 matched meals; there was no significant difference in percent food intake $(p=0.07)$.

\section{Discussion}

The sample size of this study was double that of Dunne et al., and significant differences in intake were observed between meals $(7.7 \%$ more food consumed at lunch than dinner). This indicates that the sample was of sufficient size to identify statistically significant differences. However, blue dishware did not significantly improve food intake or mitigate eating challenges compared to white dishware. Most RLWD experienced a non-significant increase of $4.8 \%$ for food intake with blue dishware, which is not a clinically meaningful difference. Yet, there was considerable variability, and $27.8 \%$ of the sample "responded" to the blue dishware. The average change in food intake for this study is much lower than that found by Dunne et al., who observed a $25 \%$ increase in percent food intake with high-contrast blue dishware [19]. This may be due to discrepancies in the shades of blue dishware. However, a direct comparison cannot be made as the shade of blue utilized was not reported by Dunne et al. It is also unclear whether their participants ate in a typical dining room or a controlled environment. The contrast between food and dishware could have been altered due to variance in the presence and colour of table settings (e.g., placemats, tablecloths), and the use of natural versus fluorescent light [25]. Such contrast alterations could have confounded the effect of dishware colour. Thus, the results of the present study have increased external validity as the intervention was completed in a real dining room environment, where researchers did not control for variations in staff, room layout, table setting, or lighting.

Dishware colour also did not reduce eating challenges. RLWD often receive eating assistance to mitigate eating challenges and increase food consumption $[11,16]$. Eating assistance facilitates food intake, regardless of dishware colour [12, 17, 28, 29]. Additionally, the ability to eat is one of the last activities of daily living to be lost with dementia $[4,18]$. Therefore, the present sample may have experienced too few eating challenges to demonstrate a difference, since those requiring eating assistance were excluded.

Results of this study highlight that the factors impacting food intake among RLWD are complex, and simple interventions may not be sufficient to improve intake. As noted in this study, some residents respond to dishware colour, but the majority did not. Multicomponent interventions tailored to the specific needs of residents are more suitable. The Making the Most of Mealtimes conceptual model and other literature suggest targeting meal quality, access, and experience when addressing the needs and challenges of RLWD [9, 12, 14, 17, 29-34]. This knowledge can be used to develop future studies and meal programs that prevent and treat malnutrition among RLWD in residential care.

\section{Limitations}

The first limitation of this study is the shade of blue dishware used (i.e., Blue Lagoon). This shade may not have produced sufficient contrast with the food, resulting in non-significant findings. Second, although a standardized checklist was used to observe eating challenges [12], some may not have been observed due to the complexity of data collection. Moreover, a validated tool for eating challenges was not used, as the only tool available is the Edinburgh Feeding Evaluation in Dementia scale, which focuses on severe eating challenges associated with eating assistance (e.g., turning head away) [35]. Third, contrast sensitivity and colour discrimination were not assessed. Yet, evidence indicates that visual deficits occur during the early stages of dementia and progress concurrently with the disease [19-22]. Thus, MoCA scores were used as a proxy for this deficit. Fourth, only 53 meals were matched because residents chose different menu options during rounds 1 and 2 of data collection. Last, this intervention was performed in one dining room within a single retirement home. As such, the dining room, serving procedures, and roles of the care staff cannot be considered representative of all memory care units. 


\section{Abbreviations}

RLWD: Residents living with dementia; MoCA: Montreal Cognitive Assessment; ANOVA: Analysis of variance.

\section{Acknowledgements}

The authors are thankful to the retirement home, staff, residents, and substitute decision-makers who participated in the present study.

\section{Authors' contributions}

$H K, R D$, and CW contributed to the study's design. RD and CW managed the data collection. JM contributed with statistical plan and advice. RD performed the data analysis and wrote the first draft of the manuscript. RD, CW, HK, and JM confirmed the results, critically reviewed subsequent drafts of the manuscript, and approved its final version. All authors read and approved the final manuscript.

\section{Funding}

This study was funded by Mitacs and Schlegel Villages. Funders were not involved in study design, data collection, data analysis, data interpretation, or manuscript creation.

\section{Availability of data and materials}

The study protocol and data collection forms are available from the corresponding author upon reasonable request. The datasets generated and analyzed during the current study are not available to researchers outside of the co-investigators due to data protection laws.

\section{Ethics approval and consent to participate}

Written and verbal informed consent was obtained from the substitute decision makers of the participants included in the analyses. Verbal assent was obtained from the participants at each meal observation. This study has been reviewed and received ethics clearance through a University of Waterloo Research Ethics Committee (ORE\#40986).

\section{Consent for publication}

$$
\text { Not applicable. }
$$

\section{Competing interests}

The authors declare that they have no competing interests.

\section{Author details}

${ }^{1}$ University of Waterloo, 200 University Ave W, Waterloo, ON N2L 3G1, Canada.

2 Schlegel-University of Waterloo Research Institute for Aging, 250 Laurelwood Drive, Waterloo, ON N2J OE2, Canada.

Received: 20 March 2020 Accepted: 17 July 2020

Published online: 23 July 2020

\section{References}

1. World Health Organization. Dementia; 2019. https://www.who.int/newsroom/fact-sheets/detail/dementia. Accessed 21 Nov 2019.

2. Cerejeira J, Lagarto L, Mukaetova-Ladinska E. Behavioral and psychological symptoms of dementia. Front Neurol. 2012;3:73.

3. Lin LC, Watson R, Wu SC. What is associated with low food intake in older people with dementia? J Clin Nurs. 2010;19(1-2):53-9.

4. Njegovan V, Man-Son-Hing M, Mitchell SL, Molnar FJ. The hierarchy of functional loss associated with cognitive decline in older persons. J Gerontol Ser A Biol Sci Med Sc. 2001;56(10):M638-43.

5. Jésus P, Desport JC, Massoulard A, Villemonteix C, Baptiste A, GindrePoulvelarie L, Lorgueuilleux S, Javerliat V, Fraysse JL, Preux PM. Nutritional assessment and follow-up of residents with and without dementia in nursing homes in the Limousin region of France: a health network initiative. J Nutr Health Aging. 2012;16(5):504-8.

6. Meyer S, Gräske J, Worch A, Wolf-Ostermann K. Nutritional status of caredependent people with dementia in shared-housing arrangements - a one-year follow-up. Scand J Caring Sci. 2015;29(4):785-92.

7. Cereda E, Pedrolli C, Klersy C, Bonardi C, Quarleri L, Cappello S, Turri A, Rondanelli M, Caccialanza R. Nutritional status in older persons according to healthcare setting: a systematic review and meta-analysis of prevalence data using MNA ${ }^{\circledR}$. Clin Nutr. 2016;35(6):1282-90.

8. Chang CC, Roberts BL. Malnutrition and feeding difficulty in Taiwanese older with dementia. J Clin Nurs. 2011;20(15-16):2153-61.

9. Keller HH, Carrier N, Slaughter SE, Lengyel C, Steele CM, Duizer L, Morrison J, Brown KS, Chaudhury H, Yoon MN, Duncan AM. Prevalence and determinants of poor food intake of residents living in long-term care. $J$ Am Med Dir Assoc. 2017;18(11):941-7.

10. Verbrugghe M, Beeckman D, Van Hecke A, Vanderwee K, Van Herck K, Clays E, Bocquaert I, Derycke H, Geurden B, Verhaeghe S. Malnutrition and associated factors in nursing home residents: a cross-sectional, multicentre study. Clin Nutr. 2013;32(3):438-43.

11. Keller HH, Lengyel C, Carrier N, Slaughter SE, Morrison J, Duncan AM, Steele CM, Duizer L, Brown KS, Chaudhury H, Yoon MN. Prevalence of inadequate micronutrient intakes of Canadian long-term care residents. Br J Nutr. 2018;119(9):1047-56.

12. Keller HH, Carrier N, Slaughter S, Lengyel C, Steele CM, Duizer L, Brown KS, Chaudhury H, Yoon MN, Duncan AM, Boscart VM. Making the Most of Mealtimes (M3): protocol of a multi-centre cross-sectional study of food intake and its determinants in older adults living in long term care homes. BMC Geriatr. 2017;17(1):15.

13. Rodríguez-Rejón Al, Ruiz-López MD, Artacho R. Dietary intake and associated factors in long-term care homes in Southeast Spain. Nutrients. 2019;11(2):266

14. Keller H, Carrier N, Duizer L, Lengyel C, Slaughter S, Steele C. Making the Most of Mealtimes (M3): grounding mealtime interventions with a conceptual model. J Am Med Dir Assoc. 2014;15(3):158-61.

15. Lin SJ, Hwang SJ, Liu CY, Lin HR. The relationship between nutritional status and physical function, admission frequency, length of hospital stay, and mortality in old people living in long-term care facilities. J Nurs Res. 2012:20(2):110-21.

16. Neyens J, Halfens R, Spreeuwenberg M, Meijers J, Luiking Y, Verlaan G, Schols J. Malnutrition is associated with an increased risk of falls and impaired activity in elderly patients in Dutch residential long-term care (LTC): a cross-sectional study. Arch Gerontol Geriatr. 2013;56(1):265-9.

17. Mann K, Lengyel CO, Slaughter SE, Carrier N, Keller H. Resident and staff mealtime actions and energy intake of long-term care residents with cognitive impairment: analysis of the making the most of mealtimes study. J Gerontol Nurs. 2019;45(8):32-42.

18. Slaughter SE, Hayduk LA. Contributions of environment, comorbidity, and stage of dementia to the onset of walking and eating disability in longterm care residents. J Am Geriatr Soc. 2012;60(9):1624-31.

19. Dunne TE, Neargarder SA, Cipolloni PB, Cronin-Golomb A. Visual contrast enhances food and liquid intake in advanced Alzheimer's disease. Clin Nutr. 2004;23(4):533-8.

20. Risacher SL, WuDunn D, Pepin SM, MaGee TR, McDonald BC, Flashman LA, Wishart HA, Pixley HS, Rabin LA, Paré N, Englert JJ. Visual contrast sensitivity in Alzheimer's disease, mild cognitive impairment, and older adults with cognitive complaints. Neurobiol Aging. 2013;34(4):1133-44

21. Cormack FK, Tovee M, Ballard C. Contrast sensitivity and visual acuity in patients with Alzheimer's disease. Int J Geriatr Psychiatry. 2000;15(7):614-20.

22. Ward ME, Gelfand JM, Lui LY, Ou Y, Green AJ, Stone K, Pedula KL, Cummings SR, Yaffe K. Reduced contrast sensitivity among older women is associated with increased risk of cognitive impairment. Ann Neurol. 2018;83(4):730-8

23. Marsiske M, Klumb P, Baltes MM. Everyday activity patterns and sensory functioning in old age. Psychol Aging. 1997;12(3):444.

24. Muurinen SM, Soini HH, Suominen MH, Saarela RK, Savikko NM, Pitkälä $\mathrm{KH}$. Vision impairment and nutritional status among older assisted living residents. Arch Gerontol Geriatr. 2014;58(3):384-7.

25. Brush JA, Meehan RA, Calkins MP. Using the environment to improve intake for people with dementia. Alzheimer's Care Today. 2002;3(4):330-8.

26. Slaughter $\mathrm{S}$, Cole $\mathrm{D}$, Jennings $\mathrm{E}$, Reimer MA. Consent and assent to participate in research from people with dementia. Nursing Ethics. 2007:14(1):27-40.

27. Montreal Cognitive Assessment. Interpretation of the MoCA; 2019. https ://www.mocatest.org/faq/. Accessed 21 Nov 2019.

28. Nowson C, Sherwin AJ, McPhee JG, Wark JD, Flicker L. Energy, protein, calcium, vitamin D and fibre intakes from meals in residential care establishments in Australia. Asia Pac J Clin Nutr. 2003;12(2):172-7. 
29. Slaughter SE, Morrison-Koechl JM, Chaudhury H, Lengyel CO, Carrier $\mathrm{N}$, Keller $\mathrm{HH}$. The association of eating challenges with energy intake is moderated by the mealtime environment in residential care homes. International Psychogeriatrics. 2020, p. 1-1.

30. Murphy JL, Holmes J, Brooks C. Nutrition and dementia care: developing an evidence-based model for nutritional care in nursing homes. BMC Geriatr. 2017;17(1):55.

31. Chaudhury $H$, Hung $L$, Badger $M$. The role of physical environment in supporting person-centered dining in long-term care: a review of the literature. Am J Alzheimer's Dis Other Dementias. 2013;28(5):491-500.

32. Dietitians of Canada. Best practices for nutrition, food service and dining in long term care homes; 2019. https://www.dietitians.ca/Downloads/ Public/2013-Best-Practices-for-Nutrition,-Food-Service-an.aspx. Accessed 21 Nov 2019.
33. Douglas JW, Lawrence JC. Environmental considerations for improving nutritional status in older adults with dementia: a narrative review. J Acad Nutr Dietetics. 2015;115(11):1815-31.

34. Liu W, Galik E, Boltz M, Nahm ES, Resnick B. Optimizing eating performance for older adults with dementia living in long-term care: a systematic review. Worldviews Evid Based Nurs. 2015;12(4):228-35.

35. Amella EJ, Lawrence JF. Eating and feeding issues in older adults with dementia: part I: assessment. J Adv Nurs. 2007;26(1):25-32.

\section{Publisher's Note}

Springer Nature remains neutral with regard to jurisdictional claims in published maps and institutional affiliations.
Ready to submit your research? Choose BMC and benefit from:

- fast, convenient online submission

- thorough peer review by experienced researchers in your field

- rapid publication on acceptance

- support for research data, including large and complex data types

- gold Open Access which fosters wider collaboration and increased citations

- maximum visibility for your research: over $100 \mathrm{M}$ website views per year

At BMC, research is always in progress.

Learn more biomedcentral.com/submissions 